Received: 19.04 .2018

Revised: 17.05 .2018

Accepted: 29.06 .2018

DOI: $10.17804 / 2410-9908.2018 .4 .014-022$

\title{
THE STUDY AND DEVELOPMENT OF POLYETHYLENE COMPOSITE ELECTRICALLY CONDUCTIVE MATERIALS
}

\author{
E. S. Petukhova ${ }^{1, a^{*}}$, P. N. Petrova ${ }^{1, b)}$, M. D. Sokolova ${ }^{1, c)}$, A. L. Fedorov ${ }^{1, d)}$, \\ A. G. Argunova ${ }^{1, \text { e) }}$, D. A. Grunenko ${ }^{2}$, and E. V. Chikachev ${ }^{2}$ \\ ${ }^{1}$ Institute of Oil and Gas Problems, SB RAS, 1 Oktyabrskaya St., Yakutsk, 677891, Russian Federation \\ ${ }^{2}$ Sakhaneftegazsbyt JSC, 3 Chiryaeva St., Yakutsk, 677000, Russian Federation \\ a) (D) https://orcid.org/0000-0002-2091-725X; $\otimes$ evgspar@ rambler.ru; \\ b) (D) https://orcid.org/0000-0002-1859-8034; $\otimes$ ppavlina@yandex.ru ; \\ c) (DD https://orcid.org/0000-0002-1934-5573; $\otimes$ marsokol@ mail.ru ; \\ d) (iD https://orcid.org/0000-0002-1718-2643; gelverb@ mail.ru; \\ e) $\otimes$ parnikova@inbox.ru \\ *Corresponding author. E-mail: evgspar@ rambler.ru \\ Address for correspondence: 677891, Yakutsk, ul. Oktyabrskaya, 1, Russian Federation \\ Tel.: 892466290 45; fax: (4112)35 7333
}

The article presents the results of research of electrically conductive materials intended for storage and transportation of fuels. Materials based on imported components and on a composition with ingredients partially replaced by domestic raw materials are developed. The obtained materials meet the requirements for the intended application, including operation in the climatic conditions of the Republic of Sakha (Yakutia).

Keywords: polyethylene, conductive compound, conductive composite, physical and mechanical characteristics, specific volumetric electrical resistance, climatic tests.

\section{Acknowledgment}

The work was performed within the state assignment from FASO Russia, No. 0377-2016-0004.

\section{References}

1. Malenahalli Halappa Naveen, Nanjanagudu Ganesh Gurudatt, Yoon-BoShim. Applications of conducting polymer composites to electrochemical sensors: A review. Applied Materials Today, 2017, vol. 9, pp. 419-433. DOI 10.1016/j.apmt.2017.09.001.

2. Ramanujam B. T. S., Annamalai Pratheep K. Conducting polymer graphite binary and hybrid composites: structure, properties, and applications. In: Vijay Kumar Thakur, ed. Hybrid Polymer Composite Materials Applications. Elsevier, 2017, pp. 1-29.

3. Yongfang Li. Conducting polymers. In: Yongfang Li, ed. Organic optoelectronic materials. Springer International Publishing, Switzerland, 2015, pp. 23-50.

4. Blythe T. and Bloor D. Electrical Properties of Polymers. Cambridge University Press, 2008, 496 p.

5. Gadeev A. Uglenapolnennye ehlektroprovodyashchie polimernye kompozitsii dlya 3D-pechati [Coal-Filled Conducting Polymer Compositions for 3D Printing]. - LAP LAMBERT Academic Publishing, 2017, 72 p. (In Russian).

6. Makarova L.E., Nesterov A.A., Moskalev V.A., Sidoruk M.L. Behavior of conducting polymer due to environmental effect // Elektronnyi Nauchnyi Zhurnal Sovremennye Problemy Nauki 
i Obrazovaniya, 2015, No. 2-2. - Available at: https://www.science-education.ru/pdf/2015/ 12-2/686.pdf (date of access: 26.03.2018). (In Russian).

7. Sheremeta I.A., Sidorov A.I. On the effect of carbon additives on the process of polymer surface electrization. In: Nauka YUUrGU, Proceedings of the 67th Scientific Conference, 2015, pp. 478-486. (In Russian).

8. Gul V.E., Shenfil L.Z. Elektroprovodyashchie polimernye kompozitsii [Conducting Polymer Compositions]. Moscow, Khimiya Publ., 1984, 240 p. (In Russian).

9. Available at: http://sngs.ykt.ru/sites/default/files/DOCUMENTS/INFORM/Klientam/2015/01_ Положение\%20o\%20тарированных\%20нефтепродуктов.pdf (in Rissian).

10. Markov V.A. Conductive polymer composites with a high positive temperature coefficient of electrical resistance for self-regulating heaters. Synopsis of Ph. D. Thesis, M., 2014, 25 p. (In Russian). 
Подана в журнал: 19.04 .2018

УДК 541.67

DOI: $10.17804 / 2410-9908.2018 .4 .014-022$

\title{
ИССЛЕДОВАНИЕ И РАЗРАБОТКА ПОЛИЭТИЛЕНОВЫХ КОМПОЗИЦИОННЫХ ЭЛЕКТРОПРОВОДЯЩИХ МАТЕРИАЛОВ
}

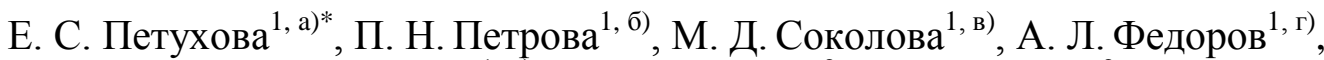 \\ А. Г. Аргунова ${ }^{1, \text { д) }}$, Д. А. Груненко 2 Э. В. Чикачев ${ }^{2}$ \\ ${ }^{1}$ ФББУН Институт проблем нефти и газа СО РАН, г. Якутск, Российская Федерация \\ ${ }^{2} \mathrm{AO}$ «Саханефтегазсбыт», г. Якутск, Российская Федерация \\ a) iD https://orcid.org/0000-0002-2091-725X; هevgspar@ rambler.ru; \\ б) iD https://orcid.org/0000-0002-1859-8034; هpavlina@yandex.ru ; \\ в) iD https://orcid.org/0000-0002-1934-5573; marsokol@ mail.ru ; \\ г) (iD https://orcid.org/0000-0002-1718-2643; gelverb@mail.ru; \\ д) $\otimes$ parnikova@inbox.ru \\ *Ответственный автор. Электронная почта: evgspar@ rambler.ru \\ Адрес для переписки: 677891, г. Якутск, ул. Октябрьская, д. 1, Российская Федерация \\ Тел.: 8-924-662-90-45; факс: (4112)35-73-33
}

В статье изложены результаты исследования электропроводящих материалов, предназначенных для хранения и транспортировки топлив. Разработаны материалы из импортных компонентов, а также с составом, ингредиенты которого частично замещены на отечественное сырье. Полученные материалы соответствуют требованиям к предполагаемой области применения, в том числе, в климатических условиях Республики Саха (Якутия).

Ключевые слова: полиэтилен, электропроводящий компаунд, электропроводящий композит, физико-механические характеристики, удельное объемное электрическое сопротивление, климатические испытания.

\section{1. Введение}

Полимерные материалы имеют некоторые ограничения по областям применения, определяющиеся их склонностью к накоплению статического электричества в процессе переработки и эксплуатации. В настоящее время речь идет не только о создании полимерных материалов, способных рассеивать статические разряды, но о все более широком применении электропроводящих композитов в области точной электроники, носителей памяти, антистатических покрытий на крупногабаритные металлические конструкции, электродов различного назначения и т. п. [1,2].

Одной из наиболее востребованных областей применения электропроводящих композитов является производство полимерной тары, предназначенной для хранения и перевозки различных нефтепродуктов. В рамках решения задачи обеспечения топливом отдаленных районов Республики Саха (Якутия) (РС(Я)) компанией АО «Саханефтегазсбыт» было организовано производство пластиковой тары и разработаны маршруты поставок, обеспечивающих бесперебойное снабжение сельских поселений, полевых подразделений геологических, горно-добывающих, строительных и иных организаций, нуждающихся в своевременном обеспечении моторными топливами. Для организации такого производства были оформлены технические условия ТУ 2297-001-52500864-2012 «Канистры полиэтиленовые для дизельного топлива и бензина», регламентирующие требования к материалу, из которого изготовлена канистра, правила техники безопасности хранения и перевозки топлив и т. п. Одним из важнейших требований к материалу является наличие постоянных электропроводных 
свойств для рассеивания статического электричества в топливе (пп. 1.3.1 ТУ). Эффективный диапазон объемного удельного электрического сопротивления для таких материалов согласно данным [8], составляет не более $10^{6} \mathrm{Oм} \cdot \mathrm{cm}$.

Придать полимерам стойкие электропроводящие свойства возможно путем строгого регулирования их структуры с созданием практически бездефектных макромолекулярных цепей с сопряженными двойными связями [3, 4]. Однако подход, заключающийся в разработке полимерных композитов, содержащих в качестве наполнителей различные электропроводящие добавки (в основном углеродные), нашел более широкое применение [5-7].

Таким образом, цель работы - разработка и исследование полиэтиленовых композиционных электропроводящих материалов со значениями объемного удельного электрического сопротивления не более $10^{6}$ Ом·см, предназначенных для хранения и транспортировки топлив.

\section{2. Материалы и методы исследования}

В качестве объектов исследования использовали как импортное, так и отечественное сырье. Первоначальный состав электропроводящего композита разрабатывался с использованием полиэтилена (ПЭ) низкого давления высокой плотности фирмы «Lotte» HDPE BL5200 (Корея) и полимерного саженаполненного компаунда на основе ПЭ низкого давления высокой плотности марки PRE-ELEC PE1296 фирмы Premix (Финляндия).

Аналогичный материал разрабатывался с использованием сырья отечественного производства. Изучение отечественного рынка позволило выделить 4 основных марки ПЭ экструзионно-выдувного назначения, предназначенных для раздува тары объемом более 20 л.: 283-73; ПЭНТ74-15; ПЭ2НТ74-17 (ПАО «Казаньоргсинтез»); РЕ6252Ј (ПАО «Нижнекамскнефтехим»). С учетом распространенности и рекомендаций производителей для дальнейших исследований использовали ПЭ марки 273-83.

Композиты изготавливали с использованием лабораторного пластикордера PL2200 Brabender (Германия) согласно технологической схеме представленной на рис. 1. ПЭ и наполнители (компаунд) смешивали в роторном смесителе пластикордера при температуре $180{ }^{\circ} \mathrm{C}$ и скорости вращения валков 30 об/мин в течение 10 мин. Полученную смесь непосредственно после смешения (практически не охлаждая) механически измельчали до необходимых размеров. Затем экструдировали ленты шириной 2-2,5 см и толщиной 1,8-2,5 мм. Длина лент определялась количеством материала.

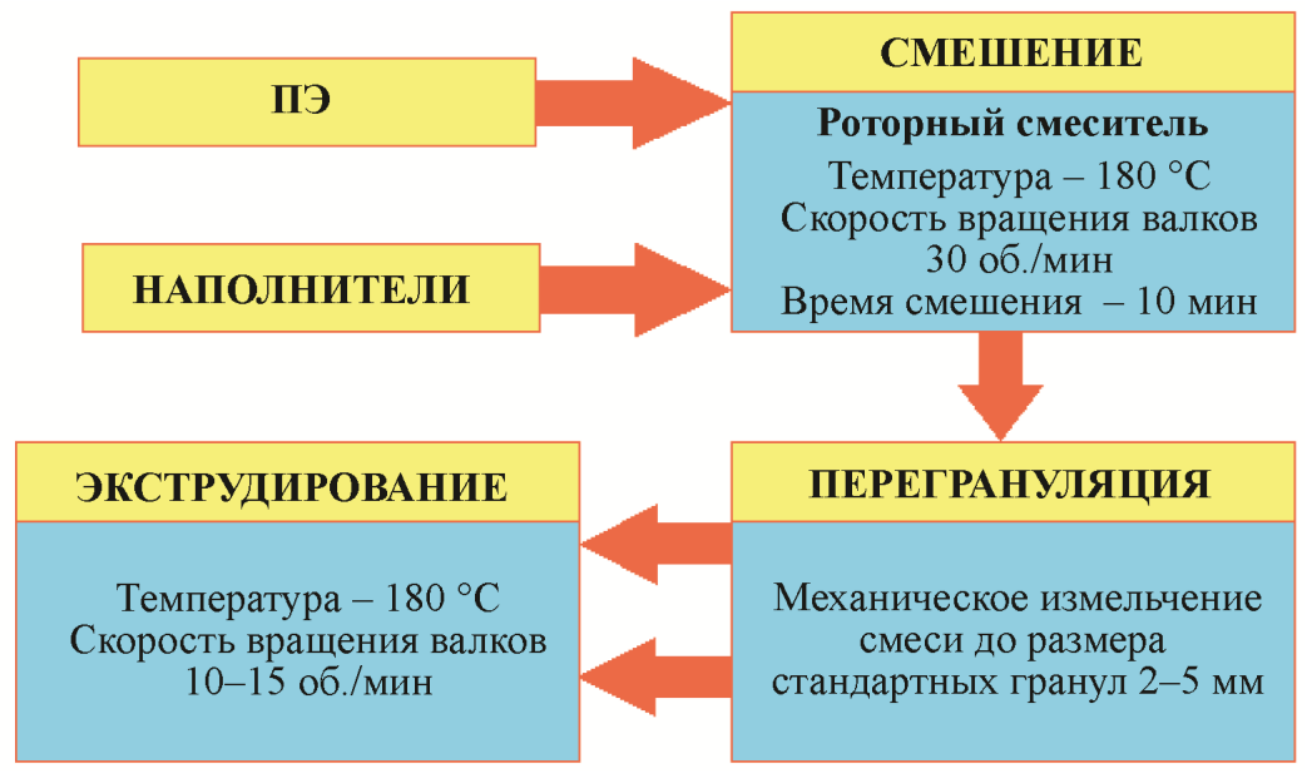

For citation: Petukhova E. S., Petrova P. N., Sokolova M. D., Fedorov A. L., Argunova A. G., Grunenko D. A., Chikachev E. V. The study and development of polyethylene composite electrically conductive materials // Diagnostics, Resource and Mechanics of materials and structures. - 2018. - Iss. 4. - P. 14-22. - DOI: 10.17804/2410-9908.2018.4.014-022. 
Рис. 1. Технологическая схема изготовления полиэтиленовых композитов

Физико-механические характеристики полученных материалов при растяжении определяли по ГОСТ 11262-80 на универсальной разрывной машине UTS-2 (Германия). Испытания проводили на образцах-лопатках Тип 5 при скорости движения траверс 50 мм/мин при комнатной температуре.

Удельное объемное электрическое сопротивление определяли по ГОСТ 20214-74. Измерение производилось по схеме, состоящей из источника постоянного напряжения, измерителя напряжения, измерителя тока, электродов и образца. Источником постоянного тока был источник питания постоянного тока Б5-49, с возможностью регулировки выходного напряжения в интервале 0,1-99,9 В, измерителем напряжения и силы тока - цифровой мультиметр Victor VC9805A+. Образцы для исследования представляли собой полоски длиной 100 мм, шириной 10 мм. Толщина образцов колебалась в диапазоне 1,8-2,5 мм. Испытания проводились при комнатной температуре.

Программа климатических испытаний разрабатываемых материалов была составлена с учетом требований ГОСТ 7.908-83. Контрольными показателями были физико-механические характеристики материалов при растяжении, плотность (ГОСТ 15139-69), набухание (ГОСТ Р ИСО 1817-2009 по аналогии с резинами) в среде бензина (АИ-92), объемное удельное электрическое сопротивление.

Плотность определяли методом гидростатического взвешивания образцов в спирте. Для исследования использовали небольшие фрагменты полиэтиленовых лент заданного состава, изъятые из разных участков испытываемого материала.

Набухание определялось как увеличение массы образцов $(20 \times 10 \times 2$ мм) после их продолжительной выдержки в агрессивной среде. Поскольку разрабатываемый материал предназначен для раздува емкостей для хранения и транспортировки бензина, в качестве агрессивной среды был выбран бензин АИ-92.

\section{3. Результаты и обсуждение}

В табл. 1 представлены значения физико-механических свойств и объемного удельного электрического сопротивления электропроводящих материалов, изготовленных из импортного сырья.

Таблица 1 - Физико-механические характеристики и удельное объемное электрическое сопротивление электропроводящих композитов на основе импортного сырья

(компаунд марки PE1296 и ПЭНД марки BL5200)

\begin{tabular}{|c|c|c|c|c|c|}
\hline $\begin{array}{c}\text { Содержание } \\
\text { РЕ1296, С, } \\
\text { мас. \% }\end{array}$ & $\begin{array}{c}\text { Модуль } \\
\text { Еугости, МПа }\end{array}$ & $\begin{array}{c}\text { Относительное } \\
\text { удлинение } \\
\text { при разрыве, } \\
\varepsilon, \%\end{array}$ & $\begin{array}{c}\text { Предел } \\
\text { текучести, } \\
\sigma_{\mathrm{T}}, \text { МПа }\end{array}$ & $\begin{array}{c}\text { Прочность } \\
\text { при разрыве, } \\
\sigma_{\mathrm{p}}, \text { МПа }\end{array}$ & $\begin{array}{c}\text { Удельное } \\
\text { объемное } \\
\text { электрическое } \\
\text { сопротивление, } \\
\rho_{\mathrm{v}}, \text { Ом·см }\end{array}$ \\
\hline 0 & 1232 & 802 & 28,1 & 16,7 & - \\
\hline 40 & 1288 & 519 & 28,2 & 16,8 & - \\
\hline 50 & 1305 & 263 & 28,5 & 17,7 & 169,0 \\
\hline 60 & 1302 & 206 & 27,6 & 17,6 & 20,6 \\
\hline 70 & 1300 & 63 & 26,9 & 17,7 & 5,5 \\
\hline 80 & 1309 & 25 & 26,9 & 18,0 & 2,3 \\
\hline 90 & 1311 & 11 & 26,4 & 20,0 & 1,1 \\
\hline 100 & 1332 & 8 & 26,0 & 22,8 & 0,6 \\
\hline
\end{tabular}


Видно, что проводимостью обладают образцы с содержанием компаунда PЕ1296 выше 50 мас. \%, причем удельное сопротивление таких материалов находится в заданном диапазоне. Снижение показателя удельного сопротивления с повышением содержания компаунда, обусловленное ростом плотности электропроводящей углеродной сетки, было не столь существенным и сопровождалось значительным снижением удлинения при разрыве. Показатели предела текучести, прочности при разрыве и модуля упругости композитов с высоким содержанием электропроводящей добавки находились на уровне композита, содержащего 50 мас. \% компаунда. Исходя из полученных результатов, для производства канистр для розлива, хранения и транспортировки топлив был рекомендован именно этот состав. Канистры из разработанного материала успешно эксплуатируются в РС(Я) в течение более чем 3 лет, согласно положению, опубликованному на сайте АО «Саханефтегазсбыт» [9].

С учетом внешней экономической политики и ростом цен на импортное сырье возникла необходимость обеспечить импортозамещение компонентов, используемых в настоящее время для производства канистр. С этой целью базовая марка ПЭ низкой плотности HDPE BL5200 была заменена на ПЭ марки 273-83 отечественного производства (ПАО «Казаньоргсинтез»).

Особенностью применения разрабатываемых материалов для канистр является эксплуатация в климатических условиях РС(Я) - после заполнения топливом канистры некоторое время хранятся в открытых проветриваемых складах производственного цеха, затем погружаются в контейнеры для перевозки, после доставки канистры также некоторое время хранятся в районных складских помещениях. С учетом климатических особенностей РС(Я) материал канистр подвергается воздействию таких факторов как высокие и низкие сезонные температуры, перепады температур, переменная влажность и т.п. Перечисленные климатические факторы могут оказать существенное влияние на эксплуатационные свойства материала, в связи с чем в настоящее время осуществляются длительные климатические исследования разрабатываемого материала. В табл. 2 представлены результаты исследования физико-механических свойств, набухания, плотности, удельного сопротивления композитов состава 50 мас. \% ПЭ марки 273-83 и 50 мас. \% компаунда РЕ1296, в том числе после 1, 3 и 6 месяцев экспонирования на испытательном полигоне Института проблем нефти и газа СО РАН (г. Якутск). Перепад температур в выбранном интервале экспонирования составлял $80{ }^{\circ} \mathrm{C}$ с минимумом при минус $47,2{ }^{\circ} \mathrm{C}$ и максимумом при $32,8^{\circ} \mathrm{C}$. Средняя температура составляла минус $14,7^{\circ} \mathrm{C}$. Контрольные образцы хранили в комнатных условиях при температуре $20-23{ }^{\circ} \mathrm{C}$.

Видно, что физико-механические характеристики полученного материала не уступают характеристикам материала, изготовленного из импортного сырья (контроль 0 мес.). Причем показатель удлинения при разрыве в 3,3 раза выше аналога. Удельное сопротивление на порядок выше, чем у материала, изготовленного из импортного сырья, однако находится в допустимом для таких материалов диапазоне.

При хранении материала в помещении (контроль 1, 3, 6 мес.) происходит некоторое снижение прочности (до 10 \%) и удлинения при разрыве (до $22 \%$ ), повышение предела текучести (до $14 \%$ ) и модуля упругости (до $13 \%$ ). Примерно такие же изменения в свойствах наблюдаются у образцов, экспонированных на полигоне.

Несколько иные закономерности прослеживаются в изменении свойств образцов, экспонировавшихся в среде бензина (АИ92). Наиболее существенные изменения характеристик проявляются после 1 мес. хранения в эксплуатационной среде - наблюдается повышение удлинения и прочности при разрыве до 15 и $19 \%$, соответственно и снижение модуля упругости до 38 \%. Однако после 6 мес. выдержки в среде бензина все свойства материала выравниваются и практически соответствуют первоначальным данным. Таким образом, не смотря на то, что изменение характеристик с течением времени наблюдаются в довольно значительном диапазоне, физико-механические показатели не падают ниже показателей материала, изготовленного из импортного сырья. 
Таблица 2 - Климатические испытания полиэтиленовых электропроводящих материалов состава ПЭ марки 273-83/PE1296 (50/50 мас. \%)

\begin{tabular}{|l|c|c|c|c|c|c|c|c|c|c|}
\hline Показатель & $\begin{array}{c}\text { Контроль } \\
(0 \text { мес. })\end{array}$ & $\begin{array}{c}\text { Контроль } \\
(1 \text { мес. })\end{array}$ & $\begin{array}{c}\text { Полигон } \\
(1 \text { мес. })\end{array}$ & $\begin{array}{c}\text { Бензин } \\
(1 \text { мес. })\end{array}$ & $\begin{array}{c}\text { Контроль } \\
(3 \text { мес. })\end{array}$ & $\begin{array}{c}\text { Полигон } \\
(3 \text { мес. })\end{array}$ & $\begin{array}{c}\text { Бензин } \\
(3 \text { мес. })\end{array}$ & $\begin{array}{c}\text { Контроль } \\
(6 \text { мес. })\end{array}$ & $\begin{array}{c}\text { Полигон } \\
(6 \text { мес. })\end{array}$ & $\begin{array}{c}\text { Бензин } \\
(6 \text { мес. })\end{array}$ \\
\hline$\sigma_{\mathrm{p}}$, МПа & 27,1 & 29,8 & 22,4 & 32,2 & 26,7 & 23,3 & 23,4 & 24,3 & 23,9 & 22,3 \\
\hline$\sigma_{\mathrm{T}}, \mathrm{MПа}$ & 23,3 & 24,8 & 25,6 & 21,4 & 23,6 & 24,8 & 22,1 & 26,7 & 26,0 & 23,4 \\
\hline$\varepsilon_{\mathrm{p}}, \%$ & 870,7 & 868,7 & 670,6 & 1001,3 & 809,5 & 677,7 & 700,9 & 675,0 & 660,5 & 622,1 \\
\hline$\varepsilon_{\mathrm{T}}, \%$ & 7,8 & 7,9 & 7,4 & 11,5 & 7,0 & 7,2 & 9,2 & 7,3 & 7,3 & 7,7 \\
\hline $\mathrm{E}, \mathrm{MПа}$ & 1222,0 & 1278,4 & 1383,8 & 886,8 & 1233,6 & 1352,2 & 1111,9 & 1400,8 & 1384,7 & 1199,9 \\
\hline$\rho, \Gamma / \mathrm{cm}^{3}$ & 1,0126 & 1,0184 & 1,0517 & 1,0461 & 1,0562 & 1,0527 & 1,0353 & 1,0218 & 1,0412 & 1,0461 \\
\hline$\Delta \mathrm{Q}, \%$ & & & & $+0,62$ & & & $+3,93$ & & & $+0,76$ \\
\hline$\rho_{\mathrm{v}}$, Ом·см & 4557,7 & 3880,7 & 24,1 & 116,9 & 2435,2 & 19,8 & 111,2 & 240,3 & 38,3 & 85,6 \\
\hline
\end{tabular}

Примечание. $\sigma_{p}$ - прочность при разрыве; $\sigma_{\mathrm{T}}$ - предел текучести; $\varepsilon_{\mathrm{p}}-$ удлинение при разрыве; $\varepsilon_{\mathrm{T}}-$ удлинение при пределе текучести; $\mathrm{E}$ - модуль упругости; $\rho$ - плотность; $\Delta \mathrm{Q}$ - набухание; $\rho_{\mathrm{v}}$ - удельное объемное электрическое сопротивление. 
Набухание в среде бензина составляет 1-4 \% и определяется, вероятно, температурой окружающей среды, продолжительностью экспонирования и процессами расширения и сжимания образцов при различных температурных условиях.

Значения удельного объемного электрического сопротивления образцов с течением времени снижаются, т. е. электропроводность материала повышается. В работе [10] рассмотрены случаи снижения объемного удельного сопротивления полимерных электропроводящих материалов при повышении температуры (вплоть до температуры плавления), что сопровождается вытеснением технического углерода в аморфные межкристаллитные области и формированием новой токопроводящей системы. Причем отмечается, что формирование таких систем продолжается и после охлаждения таких материалов (т. е. в твердом полимере). Вероятно, те же процессы происходят в рассматриваемом композите при воздействии естественных колебаний температуры окружающего воздуха, в особенности в положительном диапазоне. Система полимер/углеродный наполнитель переходит в равновесное состояние, что сопровождается формированием более равномерной электропроводящей углеродной сетки. Особенно интенсивно процесс перераспределения частиц углерода протекает в среде бензина, что вероятно связано с проникновением жидкого органического вещества (бензина) в межсферолитное пространство и вовлечением в этот процесс электропроводящих частиц, также обеспечивающее их более равномерное распределение.

\section{4. Заключение}

В результате исследований выявлено оптимальное содержание электропроводящего компаунда в полимерной матрице для обеспечения необходимого уровня удельного объемного электрического сопротивления материала.

Установлено, что замещение импортного ПЭ на ПЭ отечественной марки позволяет получить материал с необходимыми свойствами, что в дальнейшей перспективе может дать положительный экономический эффект при производстве изделий из этого материала. Кроме того, импортозамещение сырья обеспечит вовлечение в производственный процесс предприятий Российской Федерации, что в настоящее время соответствует государственной экономической политике.

Климатические испытания показали, что несмотря на некоторые изменения физикомеханических и электрических свойств, в зависимости от продолжительности экспозиции, разработанный электропроводящий композит демонстрирует пригодность к эксплуатации в качестве материала для изготовления тары, предназначенной для транспортировки и хранения бензина и других нефтепродуктов в условиях РС(Я).

\section{Благодарность}

Работа выполнена по Госзаданию ФАНО РФ 0377-2016-0004.

\section{Литература}

1. Malenahalli Halappa Naveen, Nanjanagudu Ganesh Gurudatt, Yoon-BoShim. Applications of conducting polymer composites to electrochemical sensors: A review // Applied Materials Today. - 2017. - Vol. 9. - P. 419-433. - DOI 10.1016/j.apmt.2017.09.001.

2. Ramanujam B. T. S., Pratheep K. Annamalai. Conducting polymer graphite binary and hybrid composites: structure, properties, and applications // Hybrid Polymer Composite Materials Applications / ed. by Vijay Kumar Thakur. - Elsevier, 2017. - P. 1-29.

3. Li Yongfang. Conducting polymers // Organic optoelectronic materials / ed. by Yongfang Li. - Springer International Publishing, Switzerland, 2015. - P. 23-50.

4. Блайт Э. Р., Блур Д. Электрические свойства полимеров. - М. : Физматлит, 2008. $377 \mathrm{c}$. 
5. Гадеев А. Угленаполненные электропроводящие полимерные композиции для 3D-печати. - LAP LAMBERT Academic Publishing, 2017. - 72 c.

6. Особенности поведения электропроводящего полимера в результате воздействия внешней среды / Л. Е. Макарова, А. А. Нестеров, В. А. Москалев, М. Л. Сидорук // Электронный научный журнал «Современные проблемы науки и образования». - 2015. - № 2-2. URL: https://www.science-education.ru/pdf/2015/2-2/686.pdf (дата обращения: 26.03.2018).

7. Шеремета И. А., Сидоров А. И. О влиянии углеродных добавок на процесс электризации полимерных поверхностей // Наука ЮУрГУ : материалы 67-й научной конференции, 2015. - С. 478-486.

8. Гуль В. Е., Шенфиль Л. З. Электропроводящие полимерные композиции. - М. : Химия, 1984. $-240 \mathrm{c}$.

9. Положение о порядке поступления, хранения, отпуска и учета нефтепродуктов тарированных в полиэтиленовые канистры на нефтебазах и автозаправочных станциях OAO «CАХАНЕФТЕГАЗСБЫТ». - URL: http://sngs.ykt.ru/sites/default/files/DOCUMENTS/INFORM/ /Klientam/2015/01_Положение\%200\%20тарированных\%20нефтепродуктов.pdf

10. Марков В. А. Электропроводящие полимерные композиты с повышенным положительным температурным коэффициентом электрического сопротивления для саморегулирующихся нагревателей : автореф. дис. ... канд. техн. наук. - Москва, 2014. - 25 с. 